\title{
Nurse-led multidisciplinary cooperation for early screening and protection of fecal water dermatitis in hospitalized patients with enterostomy
}

\author{
Wen-Xia $\operatorname{Lan}^{1}$, Zhe Li
}

\author{
'Department of Colorectal and Anal Surgery, Shanxi Provincial People's Hospital, \\ Taiyuan, China \\ 2Department of Nursing, Shanxi University of Chinese Medicine, Taiyuan, China
}

Submitted: 3 February 2021; Accepted: 20 July 2021

Online publication: 27 July 2021

Arch Med Sci

DOI: https://doi.org/10.5114/aoms/140355

Copyright @ 2021 Termedia \& Banach

\section{Abstract}

Introduction: This study aimed to investigate the effect of nurse-led multidisciplinary cooperation in the early screening and protection of fecal water dermatitis in hospitalized patients with enterostomy.

Material and methods: An enterostomy management team led by nurses with multidisciplinary cooperation was established to investigate the current situation of fecal water dermatitis in patients with enterostomy in our hospital, and the causes of fecal water dermatitis were analyzed. Based on the evidence-based results, the management plan for the prevention of fecal water dermatitis in patients with enterostomy was implemented. The related indicators before and after the implementation of a nurse-led multidisciplinary cooperation management program were compared.

Results: The incidence of fecal water dermatitis in patients with enterostomy decreased from $45.56 \%$ to $20.73 \%$, the screening rate of nutritional risk for patients with enterostomy increased from $45.57 \%$ to $97.56 \%$, the accuracy of stoma positioning by nurses was increased from $65.82 \%$ to $98.78 \%$, the incidence of basement warping in enterostomy was decreased from $29.80 \%$ to $1.95 \%$, the incidence of fecal water leakage decreased from $50.76 \%$ to $22.53 \%$, the one-hour leakage rate of stoma basement increased from $4.48 \%$ to $97.29 \%$, the awareness rate of patients' related knowledge increased from $43.03 \%$ to $80.48 \%$, and the average score of self-care ability of patients (family members) increased from 99.5 to 126.7 . Patients' mean quality of life scores increased from 80.73 to 98.57 , and patients' mean self-efficacy scores increased from 78.34 to 99.26 . The differences in the above indicators were statistically significant $(p<0.01)$.

Conclusions: Nurse-led multidisciplinary cooperation can improve early screening and protection of fecal water dermatitis in hospitalized patients with enterostomy and improve the quality of life of patients.

Key words: multidisciplinary cooperation, enterostomy patients, fecal water dermatitis, screening, and protection.

\section{Introduction}

As living standards gradually improve, people's eating habits change to a high protein, high fat, high energy and low fiber food diet; in addition people relieve stress by smoking and drinking alcohol, with a lack of exercise. These poor diet and lifestyle habits are among the risk fac-

\author{
Corresponding author: \\ Zhe Li \\ Department of Nursing \\ Shanxi University \\ of Chinese Medicine \\ 89 Jingci St \\ Wangboling District \\ Taiyuan 030024, China \\ Phone: +86 15703415508 \\ Fax: +8615703415508 \\ E-mail: lizhe_dr@163.com
}


tors for the increased number of colorectal cancer patients [1]. In 2012, the World Health Organization (WHO) announced the 20 countries with the largest number of new colorectal cancer cases and deaths in the world, and China ranked first [2]. As of 2017, more than 2.2 million patients have been diagnosed with colorectal cancer worldwide. There are 376,000 cases of colorectal cancer in China, and about $60 \%$ of the patients have low rectal cancer. Doctors can reduce the mortality and the incidence of postoperative anastomotic fistulae by establishing permanent or temporary enterostomy [3-6]. Enterostomy refers to the operation used to treat some intestinal diseases (such as rectal cancer and colon cancer). A surgeon will pull out a section of the intestinal lumen, turn it over, and sew it to the abdominal wall, thus forming an artificial opening [7]. There are more than 1 million patients with enterostomy in China, and the incidence of complications ranges from $22.8 \%$ to as high as $42.6 \%[8,9]$. Fecal water dermatitis is one of the common complications after enterostomy, and $45 \%$ of patients develop different degrees of fecal water dermatitis after the operation [10]. This not only increases the economic burden of patients [11] but also seriously affects the confidence of patients' postoperative rehabilitation and quality of life [12].

In the present study, 79 patients with enterostomy in our hospital from April to July 2017 were examined, and 36 patients had fecal water dermatitis. The incidence was $45.56 \%$, while the incidence in Chinese counterparts was only $22.80 \%$ [13]. In other countries, group interaction [14] and systematic management models [15] have been adopted for patients with fecal water dermatitis, achieving remarkable results. Early screening and prevention of fecal water dermatitis in patients with enterostomy in China are still in their infancy. However, the nutritional support of clinical medical staff in our department for patients with fecal water dermatitis is low and does not meet patients' needs. In clinical practice, there is a lack of scientific and reasonable protective measures, and no effective management model has been established. Researchers such as Bai [16] found that in the multidisciplinary management of early postoperative dysphagia screening and rehabilitation of patients with cerebral hemorrhage, nurse-led multidisciplinary management has a significant effect. Therefore, in this study, through the establishment of nurse-led multidisciplinary cooperation in the management of enterostomy, we implemented a management plan of prevention of fecal water dermatitis in patients with enterostomy to identify and prevent fecal water dermatitis early and reduce the incidence of fecal water dermatitis and improve patients' quality of life. The details are reported as follows.

\section{Material and methods}

\section{Establish a nurse-led multidisciplinary enterostomy management team}

Under the colorectal cancer multidisciplinary team in our hospital, a nurse-led multidisciplinary enterostomy management team was established. The members include the following: four colorectal surgeons, one head nurse, two enterostomy therapists, five charge nurses, two information engineers, one dietitian, one clinical laboratory physician, and one logistics master.

Based on the multidisciplinary team of colorectal cancer in our hospital, a multidisciplinary enterostomy management team led by the nursing dean has been established, which consists of the nursing department, the medical department, the nutrition department, the laboratory department, the logistics department and the information department, and the three-step enterostomy management framework is composed of special administrators of each department. The construction team consisted of 4 colorectal surgeons, 1 head nurse, 2 enterostomy therapists, 5 nurses as cashiers, 2 information engineers, 1 nutritionist, 1 laboratorian, and 1 logistics master.

The relationships and roles of personnel of our colorectal cancer multidisciplinary team are shown in Figure 1.

\section{Selection of participants}

Inclusion criteria: (1) patients who underwent ileostomy, transverse colostomy, and sigmoid colostomy; (2) patients who could read and write; (3) patients without senile dementia; and (4) patients and their families provided signed informed consent. Exclusion criteria: (1) patients with mental illness and communication disorders; (2) patients with conscious disturbance or severe cognitive impairment; and (3) patients with language communication impairment. The study was conducted in accordance with the Declaration of Helsinki (as revised in 2013). The study was approved by the Ethics Committee of Shanxi University of Chinese Medicine and informed consent was taken from all the patients.

\section{Implementation of early screening and protection measures of fecal water dermatitis in patients with enterostomy}

According to the results of the evidence-based process, the "multidisciplinary procedure for prevention of fecal water dermatitis in patients with enterostomy" was formulated, as shown in Figure 2. 


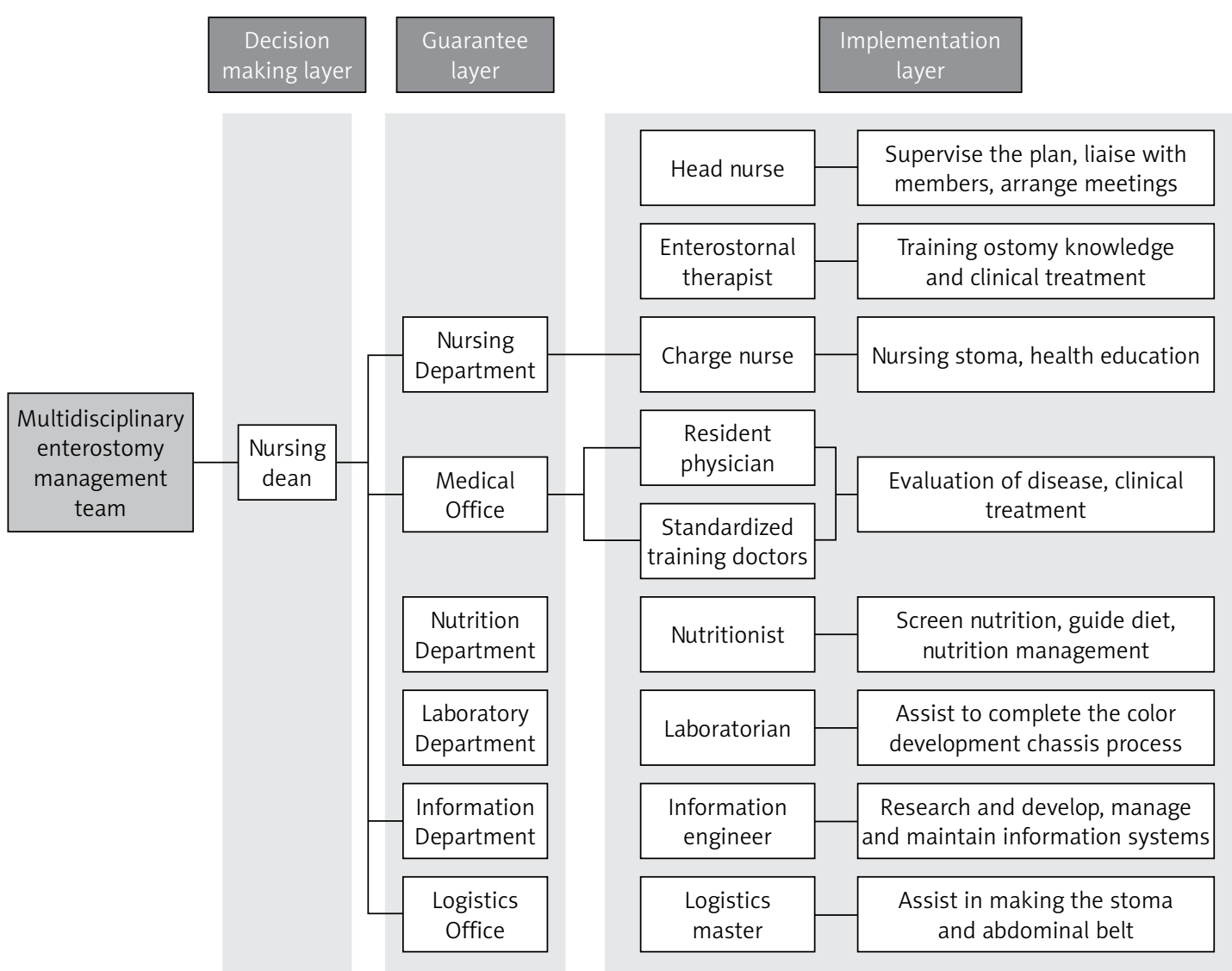

Figure 1. Relationships and roles of personnel of our colorectal cancer multidisciplinary team

Specific implementation steps:

Revise the nutrition management system

for patients with enterostomy

The low screening rates and long intervention times were analyzed, including the following: (1) Single assessor: evaluation was carried out relying on the dietitian only. Due to the large number of inpatients, the ward was not equipped with a full-time nutrition manager, so patients waited a long time for evaluation. (2) The intervention time of assessors was long: the nutritionist's intervention time was up to $72 \mathrm{~h}$, resulting in malnutrition, fistula retraction, and difficulty in excreta collection.

Improvement of measures: (1) The training and assessment of nutrition screening for nurses by nutrition doctors were as follows: the content and knowledge of nutrition screening forms were taught, and the nurses' qualification rate was more than $90 \%$. (2) After admission, 1-5 days after surgery, the responsible nurse used the NRS2002 Nutritional Risk Assessment form [17] to screen patients' nutritional risk; dietitian intervention was performed for those with a score of $\geq 3$. (3) Based on the results of nurses' nutritional assessment, the nutrition department doctors implemented dynamic nutritional management for patients at nutritional risk within $48 \mathrm{~h}$, and colorectal surgeons and nutritionists worked out a nutrition treatment plan together.

\section{Construction of nurse-led whole process management model with enterostomy patients as the center}

The existing factors of imperfect nursing measures for enterostomy were analyzed. The correct rate of stoma positioning by nurses was low. The early detection rate of fecal water leakage (within $1 \mathrm{~h}$ ) was only $4.48 \%$. The traditional enterostomy abdominal belt rolls up easily at the edge, causing basement edge warping and fecal water leakage.

Improvement of measures: (1) General nurses were trained in combining theory with practice: first, enterostomy therapists trained nurses in stoma structure, positioning, and nursing. Then, the head nurse explained the specific content of the PIO physical assessment kit and carried out clinical guidance and assessments. Before enterostomy, under the doctors' guidance, the responsible nurses and doctors jointly completed the preoperative stoma positioning and health guidance. First of all, the ostomy surgeon developed a training plan for theory and clinical practice. The training period was 2 months, twice a week, 50 min each 


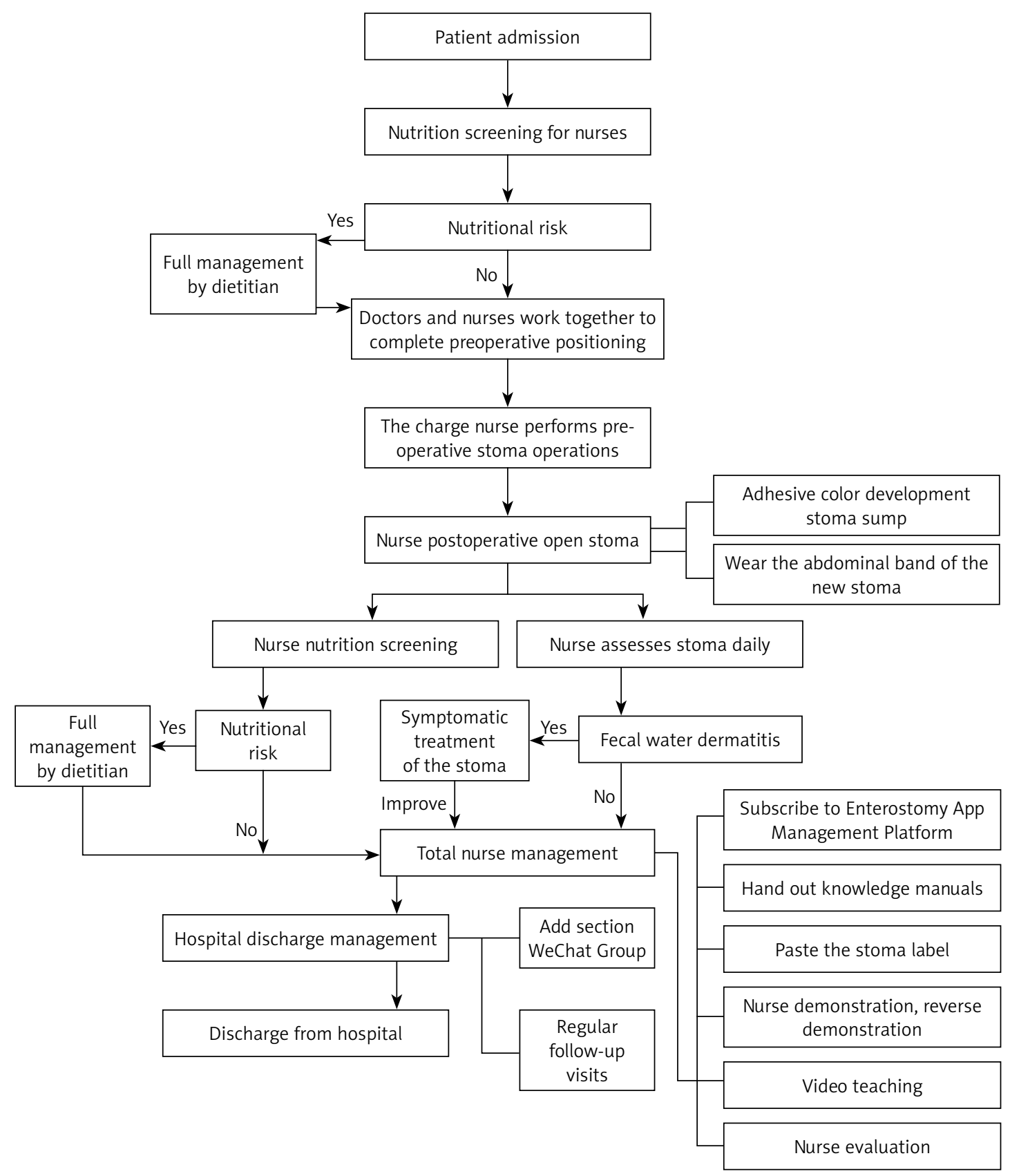

Figure 2. Multidisciplinary protection process of fecal water dermatitis in patients with enterostomy

time. The theoretical teaching was conducted in the form of PPT combined with blackboard writing, including the physiological structure of enterostomy, positioning of enterostomy and enterostomy nursing knowledge. Clinical practice teaching was conducted in the form of mutual simulation of patients by responsible nurses, and the training contents included the use of a PIO body evaluation kit, measurement and cutting of the ostomy chassis, pasting the ostomy bag and basic skills of ostomy nursing, etc. (2) On the day of the operation, a stoma basement was prepared on the colored bowel. The laboratory physician selected the color reagent, and the information engineer drew the colored stoma basement drawing. The imaging layer was added on one side of the basement body. When the basement meets the fecal water, it turns green so nurses can find the fecal water leakage in time and replace the stoma basement. (3) On the day of the operation, the new enterostomy abdominal belt was worn. The information engineer drew the structural drawings of the new type of abdominal belt, and the logistics master thickened the abdominal belt. The belt supports the patient's waist and could reduce the displacement of the abdominal belt, avoid basement warping, and reduce fecal water leakage. (4) Standardizing the shift handover process for 
enterostomy patients: The items of stoma exhaust, color, basement, bracket, and stitching removal were added to the shift handover record sheet. During shift handovers, rose signs were added at the head of the bed to remind the nurses on each shift to observe the stoma condition of patients and carry out nutritional risk screening. (5) The Self-Management Manual for Patients with Enterostomy was issued and explained in detail on the first and second day after the operation. (6) On days 3-5 after the operation, the responsible nurse demonstrated the nursing process of enterostomy to the patients and their families. When the basement was replaced for the second time, the patients and their family members were instructed to take enterostomy care by reverse teaching. Stomatologists used adhesive pressure tools to explain and demonstrate the adhesion method of the stoma basement. They also recorded the construction of stoma pockets, demonstrated adhesive pressures of stoma basements, the replacement of stoma basements and stoma pockets, and nursing of the stoma and surrounding skin into educational videos. Nurses arranged for patients and their families to watch the video together in the training classroom and uploaded it to the information platform for patients to learn by themselves. (7) On the sixth day after the operation, the responsible nurses scored the patients by using the Evaluation Guidance Sheet and the Self-Care Ability Evaluation Sheet for Patients with Enterostomy, then strengthened the education of content that the patients did not understand. (8) Before discharge, the responsible nurse taught patients to use the APP Management Platform for Enterostomy Patients and invited patients to join the WeChat group established by medical staff for regular follow-up. Follow-up was conducted 1 week, half a month and 3 months after discharge. Follow-up was conducted in the form of WeChat, telephone and APP management platform.

\section{Information management of patients with enterostomy based on APP management platform}

The imperfect information platform factors were analyzed. The existing official account of WeChat only pushes the knowledge of enterostomy and cannot interact with patients. The layout lacks the knowledge that patients find easy to accept and cannot meet patients' needs.

Improvement of measures: Based on an Addie model, we made a questionnaire to investigate the general situation, psychological status, self-efficacy, and quality of life of patients with enterostomy. This questionnaire was to help us understand the needs of patients with enterostomy. We designed an enterostomy health education knowl- edge module with information department engineers, created an APP management platform for patients with enterostomy, and built the hospital and patient site. The responsible nurses provided individualized guidance for patients with enterostomy through the APP management platform and completed remote follow-up after discharge to complete the information-based and intelligent whole process management.

\section{Quality control}

(1) Completing the nursing records: The record sheet included the first nutritional screening of patients with enterostomy, the time of nutritional management intervention, the accurate positioning of the stoma before the operation, the screening of early detection of fecal water dermatitis (within $1 \mathrm{~h}$ ), and the edge warping of the stoma basement.

(2) The colorectal surgery specialist nursing quality index was used for quality control analysis. Based on the literature review, evidence-based results, and expert consultation, the incidence of fecal water dermatitis in patients with enterostomy was set as the main index of specialized nursing in colorectal surgery. Other secondary quality indicators included the screening rate by nurses of nutritional risks for patients with enterostomy, the correct positioning rate of enterostomy for patients by responsible nurses, the incidence of basement warping for patients with enterostomy, the incidence of fecal water leakage, the incidence of stoma basement leakage in the early stage (within $1 \mathrm{~h}$ ), the awareness rate of relevant knowledge of enterostomy patients, and the self-care ability of patients with enterostomy (family members). Enterostomy therapists acted as quality control specialists. They registered the above indicators daily, conducted statistical analysis every month, fed back the existing problems in the department's morning meeting, and continuously improved the quality to reduce the incidence of fecal water dermatitis in patients with enterostomy.

(3) Strengthening communication and learning among members: A WeChat group was set up to provide feedback on patients' condition information, adjust patients' treatment and nutritional support plans, and send new guidelines and materials for members to learn.

\section{Statistical analysis}

Statistical software SPSS22.0 was used for statistical analysis of data. Count data were described as frequency. Measurement data were described as mean \pm standard deviation $(x \pm$ SD) and percentage (\%). The scores of age and self-care ability were normally distributed and compared 
using two independent sample $t$-tests. Gender education level, body mass index (BMI), the incidence of fecal water dermatitis, nutrition screening rate, correct positioning rate of the stoma, awareness rate of relevant knowledge of patients, the incidence of basement warping, the incidence of fecal water leakage, and the incidence of stoma basement leakage in the early stage (within $1 \mathrm{~h}$ ) were compared using the $\chi^{2}$ test, in which the BMI was compared using Fisher's exact test. $P<0.05$ was considered statistically significant.

\section{Results}

\section{General data}

According to the inclusion and exclusion criteria, the number of patients in the experimental group and the control group was selected by the random number table method; 79 patients with enterostomy in the Department of Anorectal Surgery of Shanxi Provincial People's Hospital from April to July 2017 were enrolled in this study as the control group. Among these patients, 27 were male, and 52 were female. The patients' age range was $29-78$ years, with an average age of $57.61 \pm 11.44$. A total of 82 patients with enterostomy from January to June in 2019 were enrolled in this study as the experimental group. Among these patients, 38 were male, and 44 were female. These patients' age range was $29-80$ years, with an average age of $57.16 \pm 10.32$. The t test or $\chi^{2}$ test was performed on age, gender, degree of education and BMI between the experimental group and control group; the differences in general data between the two groups were not statistically significant, as shown in Table I. All patients provided signed informed consent.
Problems of fecal water dermatitis of patients with enterostomy

Field investigation showed that $50.67 \%$ of patients with enterostomy had fecal water leakage, which is the main cause of fecal water dermatitis. Through the cause analysis, the following factors were obtained: (1) The screening rate of nutritional risk was only $45.57 \%$. (2) The nutrition intervention time of the dietitian was $72 \mathrm{~h}$, which was $48 \mathrm{~h}$ more than that required for consultation. (3) The correct rate of stoma positioning was only $65.82 \%$ because the enterostomy therapist completes routine stoma positioning. In emergencies or when the enterostomy therapist is unavailable, the responsible nurse's positioning is not always accurate, which leads to poor adhesion of the stoma basement. (4) The early detection rate of fecal water leakage was only $4.48 \%$. Due to the thick material and deep color of the traditional stoma basement, it is not easy to find fecal water leakage. (5) The edge warping rate of the stoma basement was $29.8 \%$. (6) The information system is not perfect: the enterostomy information on the existing WeChat public platform is relatively in complete and cannot meet the needs of patients and their families. This results in patients' poor self-care ability, with an average score of only 99.5 points.

\section{Data of main outcome indicator}

The main outcome indicator was the incidence of fecal water dermatitis. The incidence of fecal water dermatitis was $45.6 \%$ before intervention and decreased to $7 \%$ after intervention. The difference between the two groups was statistically significant $(p<0.01$, Table II).

Table I. Comparison of general data between two groups of patients (cases/\%)

\begin{tabular}{|c|c|c|c|c|c|c|c|c|}
\hline \multirow[t]{2}{*}{ Groups } & \multirow{2}{*}{$\begin{array}{c}N \\
\text { (case) }\end{array}$} & \multirow{2}{*}{$\begin{array}{l}\text { Age }(x \pm s) \\
\text { [years] }\end{array}$} & \multicolumn{2}{|c|}{ Gender } & \multicolumn{2}{|c|}{ Degree of education } & \multicolumn{2}{|c|}{ BMI $\left[\mathrm{kg} / \mathrm{m}^{2}\right]$} \\
\hline & & & Male & Female & $\begin{array}{l}\text { Below } \\
\text { junior } \\
\text { middle } \\
\text { school }\end{array}$ & $\begin{array}{l}\text { Above } \\
\text { junior } \\
\text { middle } \\
\text { school }\end{array}$ & $<18.5$ & $\geq 18.5$ \\
\hline Control group & 79 & $57.61 \pm 11.44$ & $27(34.17)$ & $52(65.83)$ & $36(45.57)$ & $43(54.43)$ & $5(6.33)$ & $74(93.67)$ \\
\hline $\begin{array}{l}\text { Experimental } \\
\text { group }\end{array}$ & 82 & $57.16 \pm 10.32$ & $38(46.34)$ & $44(53.66)$ & $38(46.34)$ & $44(53.66)$ & $4(4.88)$ & $78(95.12)$ \\
\hline$t / \chi^{2}$ value & & 0.069 & \multicolumn{2}{|c|}{2.473} & \multicolumn{2}{|c|}{0.010} & \multicolumn{2}{|c|}{0.161} \\
\hline$P$-value & & 0.794 & \multicolumn{2}{|c|}{0.116} & \multicolumn{2}{|c|}{0.922} & \multicolumn{2}{|c|}{0.689} \\
\hline
\end{tabular}

Table II. Comparison of the incidence of fecal water dermatitis between the two groups (cases/\%)

\begin{tabular}{|c|c|c|c|}
\hline Groups & $N$ & Fecal water dermatitis & No fecal water dermatitis \\
\hline Control group & 79 & $36(45.56)$ & $43(54.44)$ \\
\hline Experimental group & 82 & $17(20.73)$ & $65(79.27)$ \\
\hline$\chi^{2}$ value & & & \\
\hline$P$-value & & & \\
\hline
\end{tabular}




\section{Secondary outcome indicators}

Secondary outcome indicators include the following: nutrition screening rate, correct stoma positioning rate, awareness rate of patients' knowledge, self-care ability of patients with enterostomy (family members), living quality, self-efficacy, the incidence of basement warping in enterostomy, the incidence of fecal water leakage, and the leakage rate of the stoma basement in the early stages (within $1 \mathrm{~h}$ ). The differences between the two groups were statistically significant $(p<0.01$, Tables III and IV).

\section{Discussion}

Nurse-led multidisciplinary cooperation is important in the management of fecal dermatitis in enterostomy patients

The multidisciplinary team implemented standard, individualized, and fully comprehensive process management to patients with enterostomy, and then found fecal water leakage of enterostomy patients and conducted effective protection, which could reduce occurrence of fecal dermatitis. Currently, some researchers in China use the cluster care mode for enterostomy patients [18], but most of the hospitals are still at the starting stage of managing enterostomy patients, so they lack scientific and reasonable management in clinical practice. Before establishing the multidisciplinary team, nurses always took care of the colostomy with their knowledge and each department lacked effective communication. Also, most of the nurses took care of the enterostomy patients by depending on their nursing experience or following the doctors' advice, so there are still some gaps to fill to achieve comprehensive care. Therefore, it is necessary to have a multidisciplinary team that can provide high-quality standard management [19]. While doctors have been dominant in most of the multidisciplinary teams rather than nurses, who have less decision-making authority, the nurse-led multidisciplinary team conforms to the trend of medical development and it would promote communication and cooperation among disciplines, reduce risks and potential hazards, and avoid the drawbacks of the traditional mode [20, 21]. Ostomy nurses have absolute advantages at managing enterostomy patients and can follow up the patients' situation after they are discharged from the hospital, so it is more advantageous to let a nurse-led team implement this study.

This study introduced the concept of multidisciplinary team cooperation, and it used the nurseled team as a hub, linking multiple departments and establishing a multidisciplinary cooperation management mode for patients with enterostomy as the focus. In the whole process, the multidisciplinary team was responsible for the patients' hospital admission, before surgery, after surgery, discharge from hospital, and follow-up visits. They also had a deep understanding and dynamic assessment of, and immediate intervention in, the patients' condition. With the nurse-led team dealing with hospital admission and nutritional screening during surgery, it was effective to shorten the timing for the dietary nutritionist, so that patients could get effective treatment as early as possible after the doctor in charge made a normative treat-

Table III. Comparison of secondary outcome indicators between the two groups (cases/\%)

\begin{tabular}{|lccccccc|}
\hline Groups & $\begin{array}{c}\boldsymbol{N} \\
\text { (case) }\end{array}$ & $\begin{array}{c}\text { Nutritional } \\
\text { risk screen- } \\
\text { ing }\end{array}$ & $\begin{array}{c}\text { Correct } \\
\text { positioning } \\
\text { of stoma }\end{array}$ & $\begin{array}{c}\text { Aware- } \\
\text { ness rate } \\
\text { of related } \\
\text { knowledge } \\
\text { of patients }\end{array}$ & $\begin{array}{c}\text { Self-care } \\
\text { ability }\end{array}$ & $\begin{array}{c}\text { Living } \\
\text { quality }\end{array}$ & Self-efficacy \\
\hline Control group & 79 & $36(45.57)$ & $52(65.82)$ & $34(43.03)$ & $99.50 \pm 7.16$ & $80.73 \pm 8.32$ & $78.34 \pm 19.92$ \\
\hline $\begin{array}{l}\text { Experimental } \\
\text { group }\end{array}$ & 82 & $80(97.56)$ & $81(98.78)$ & $66(80.48)$ & $126.70 \pm 3.77$ & $98.57 \pm 9.34$ & $99.26 \pm 18.13$ \\
\hline$t / \chi^{2}$ value & 54.008 & 30.421 & 23.979 & 1.526 & 6.531 & 7.348 \\
\hline$P$-value & $<0.01$ & $<0.01$ & $<0.01$ & 0.018 & $<0.01$ & 0.032 \\
\hline
\end{tabular}

Table IV. Comparison of secondary outcome indicators between the two groups (cases/\%)

\begin{tabular}{|lcccc|}
\hline Groups & $\begin{array}{c}\text { Total } \\
\text { days }\end{array}$ & $\begin{array}{c}\text { Incidence of basement } \\
\text { warping }\end{array}$ & $\begin{array}{c}\text { Incidence of fecal water } \\
\text { leakage }\end{array}$ & $\begin{array}{c}\text { Leakage rate of stoma } \\
\text { basement in early stage } \\
\text { (within 1 h) }\end{array}$ \\
\hline Control group & 792 & 29.80 & 50.76 & 4.48 \\
\hline Experimental group & 821 & 1.95 & 22.53 & 97.29 \\
\hline$\chi^{2}$ value & 36.654 & 24.192 & 43.159 \\
\hline$P$-value & $<0.01$ & $<0.01$ & $<0.01$ \\
\hline
\end{tabular}


ing plan based on the nutritional assessment. According to Ayik et al. [22], with nurses' care and follow-up procedures for enterostomy patients, there was an effective reduction in complicating disease occurrence rate. The multidisciplinary team performed standard, individualized, and comprehensive process management for every enterotomy patient, and cooperated with Yuanli Guo et al. as a multidisciplinary team. They obtained good study results during the process in the practice of improving the nutrition of patients with dysphagia after stroke. Nursing played a crucial role in managing enterostomy patients. Therefore, it emphasized once again that a nurse-led team would be more favorable to implement the study, and it is also a reliable assurance for enterostomy patients.

\section{Feasibility analysis of nurse-led multidisciplinary cooperation in the management of fecal dermatitis in enterostomy patients}

According to Luo et al. [23], the occurrence rate of fecal dermatitis decreased through the nursing intervention, which is consistent with the results of this study. It developed a "multidisciplinary prevention process of fecal dermatitis in enterostomy patients" according to the evidence-based results, which is a more scientific method as it provides patients with intelligent, informative, and fully processed multidisciplinary management through establishing a nurse-led multidisciplinary enterostomy management team. After carrying out nurse-led multidisciplinary cooperation, there is a significant difference in leading and secondary indicators compared to the results before establishing a multidisciplinary team. Both indicators have statistical significance $(p<$ 0.01). The use of the stoma basement allows for the timely replacement of the stoma basement when fecal leakage is detected at an early stage (within $1 \mathrm{~h}$ ), thus shortening the time of fecal irritation of the skin and ultimately enabling early screening for fecal dermatitis. Also it provided the most effective protection against fecal water leakage. Through the intervention of nurse-led multidisciplinary cooperation, enterostomy patients not only improved their standard of living but also enhanced their self-efficiency and confidence in triumphing over the disease. Thus, it is feasible to establish nurse-led multidisciplinary cooperation for the treatment and nursing of patients with enterostomy.

Nurse-led multidisciplinary cooperation in the management of fecal dermatitis in patients with enterostomy promotes the development of nursing specialization

One important measurement index of professional nursing standards is the rapid development of clinical nursing specialization. Enterostomy specialized nursing in western countries was developed earlier than that in China and gradually became standardized. However, with the change of the disease spectrum, many complications have been occurring, so it is more challenging to deal with difficult enterostomy, which is also an important research project that researchers and specialized nurses have been working on in some countries [24]. It is more meaningful to prevent fecal dermatitis from happening in enterostomy patients compared to treatments. Severe cases often relate to specialization such as nutrition, medicine, infection, and other problems. Usually, these patients are a high-risk group within whom fecal dermatitis may occur, so linking multiple disciplines together to achieve our goals is the number one priority to prevent and treat fecal dermatitis [25]. The rate of increase to educate specialized enterostomy nurses is much slower than the rate of increase in number of patients, which restricts enterostomy nursing and causes many other issues [26]. It is a great opportunity to establish an advanced and specialized team if medical resources can be coordinated, further optimized, joint consultation and inspection can be developed, and the urgent treatment, nursing, and recovery can be combined. The establishment of a nurse-led multidiscipline mode provides us with a platform that we need. From start to end, the nurse-led multidisciplinary team provides nursing and monitoring during a hospital stay, also adjusts the nursing plan dynamically, and tracks the condition of patients requiring continued nursing services, which can increase patients' confidence, and deliver the smooth transition from hospital to home. These are the current and future goals that require all medical staff to join their efforts to achieve them.

\section{Acknowledgments}

We are grateful to all the people who have given us help in our study.

\section{Conflict of interest}

The authors declare no conflict of interest.

\section{References}

1. de'Angelis N, Baldini C, Brustia R, et al. Surgical and regional treatments for colorectal cancer metastases in older patients: a systematic review and meta-analysis. PLoS One 2020; 15: e0251005.

2. Armstrong KA, Coyte PC, Brown M, Beber B, Semple JL. Effect of home monitoring via mobile app on the number of in-person visits following ambulatory surgery: a randomized clinical trial. JAMA Surg 2017; 152: 622-7.

3. World Health Orgnization. Global 2012:estimated cancer incidence, mortality and prevalence worldwide 
in 2012. International Agency for Research on cancer (IARC) (2012), 2014 [2016-11-15]

4. Chen HD, Dai M. On prevention and control strategy of colorectal cancer in China. Chin J Epidemiol 2020; 41: 1627-2.

5. Mattiuzzi C, Sanchis-Gomar F, Lippi G. Concise update on colorectal cancer epidemiology. Ann Transl Med 2019; 7: 609.

6. Longchamp G, Meyer J, Abbassi Z, et al. Current surgical strategies for the treatment of rectal adenocarcinoma and the risk of local recurrence. Dig Dis 2021; 39: 325-33.

7. Wong MC, Avanzini S, Mosconi M, et al. Enterostomy-related complications in Hirschsprung's disease in a single cohort. Minerva Pediatr 2019; DOI: 10.23736/ S0026-4946.19.05593-2.

8. Wu XL, Wang LK, Huang XT, et al. Retrospective study on the epidemiological characteristics of colorectal cancer. China Med Herald 2019; 16: 60-3.

9. Carlsson E, Fingren J, Hallén AM, Petersén C, Lindholm E. The prevalence of ostomy-related complications 1 year after ostomy surgery: a prospective, descriptive, clinical study. Ostomy Wound Manage 2016; 62: 34-48.

10. Malik T, Lee MJ, Harikrishnan AB. The incidence of stoma related morbidity - a systematic review of randomised controlled trials. Ann R Coll Surg Engl 2018; 100: 501-8.

11. Taneja C, Netsch D, Rolstad BS, Inglese G, Lamerato L, Oster G. Clinical and economic burden of peristomal skin complications in patients with recent ostomies. J Wound Ostomy Continence Nurs 2017; 44: 350-7.

12. Maydick-Youngberg D. A descriptive study to explore the effect of peristomal skin complications on quality of life of adults with a permanent ostomy. Ostomy Wound Manage 2017; 63: 10-23.

13. Zhou XH. Advances in the care of peri-enterostomy fecal dermatitis. Today Nurse 2018; 25: 13-5.

14. Karabulut HK, Dinç L, Karadag A. Effects of planned group interactions on the social adaptation of individuals with an intestinal stoma: a quantitative study. J Clin Nurs 2014; 23: 2800-13.

15. Khalilzadeh Ganjalikhani M, Tirgari B, Roudi Rashtabadi O, Shahesmaeili A. Studying the effect of structured ostomy care training on quality of life and anxiety of patients with permanent ostomy. Int Wound J 2019; 16: 1383-90.

16. Bai HH, Yao QJ, Zhu XJ, et al. Dysphagia screening and rehabilitation nursing of cerebral hemorrhage patients in postoperative early stage. Chin J Nurs 2013; 48: 299-301.

17. Rabito El, Marcadenti A, da Silva Fink J, Figueira L, Silva FM. Nutritional Risk Screening 2002, Short Nutritional Assessment Questionnaire, Malnutrition Screening Tool, and Malnutrition Universal Screening Tool are good predictors of nutrition risk in an emergency service. Nutr Clin Pract 2017; 32: 526-32.

18. Guo YL, Dong XF, Yang CX, et al. Practice of multidisciplinary team to improve nutritional outcomes of patients with post-stroke dysphagia. Chin Nursing Manag 2019; 19: 662-6.

19. Wilkinson J, Carryer J, Budge C. Impact of postgraduate education on advanced practice nurse activity - a national survey. Int Nurs Rev 2018; 65: 417-24.

20. Cable S, Graham E. "Leading Better Care": an evaluation of an accelerated coaching intervention for clinical nursing leadership development. J Nurs Manag 2018; 26: 605-12.

21. Indreb KL, Aasprang A, Olsen TE, et al. A new model of patient-reported outcome monitoring with a clinical feedback system in ostomy care: rationale, description and evaluation protocol. Health Qual Life Outcomes 2020; 18: 12.

22. Ayik C, Zden D, Cenan D. Ostomy complications, risk factors, and applied nursing care: a retrospective, descriptive study. Wound Manag Prev 2020; 66: 20-30.

23. Luo WX, Shi XR. Effect of nursing intervention on fecal water dermatitis after ileostomy. Electronic J Pract Clin Nurs Sci 2020; 5: 81-3.

24. White M. Stoma care nurses: always ready to rise to the challenge. Br J Nurs 2020; 29: S3.

25. Barry H. Stoma care: procedures, appliances and nursing considerations. Br J Nurs 2020; 29: S14-9.

26. Carter P. Recognising the importance of stoma care nurse specialists. Br J Nurs 2020; 29: S4. 